\title{
Verbal-nonverbal Congruence or Veracity (V2) in the System for Analysis of Validity in Evaluation (SAVE)
}

DOI: $10.46932 / \mathrm{sfjdv2n2-205}$

Received in: March 1st, 2021

Accepted in: May 30th, 2021

\author{
Alicia Juárez Bielsa \\ Sección de Análisis de Conducta, Policía Nacional. Madrid, Spain. \\ E-mail: alicia_juarez@hotmail.com
}

\section{VERACITY OR CONGRUENCE}

In SAVE (López, et al, 2018) Veracity (V2) refers to the harmonic congruence (adequate synchrony, intensity, and relationship) between the verbal content, already studied in V1 and the nonverbal behavior that accompanies it. The concordance between the verbal message emitted and the non-verbal communication that derives from the cognitive and emotional processes of the subject is related to characteristics of honesty and sincerity in the speeches.

\section{FEAP PROTOCOL (FACIAL EXPRESSION ANALYSIS PROTOCOL)}

The FEAP protocol (Facial Expression Analysis Protocol) developed by López, Soto, Gordillo, and Pérez-Nieto (2014) is based on the scientific and controlled observation of the subject's behavior based on three theoretical pillars supported by new discoveries in modern psychology:

(a) Basic emotions. Characterization

The evolutionary study of emotions proposes the existence of unique and distinctive characteristics for each emotional category, which would allow us to speak of discrete or specific emotions despite the individual differences that arise in the personal development of each one of them (Ekman, 1972; Izard, 1991; Tomkins, 1962, 1963). Among these distinctive characteristics one could delimit:

- Correspondence between the type of event and the emotional form itself.

- Facial expression, which will be universal.

- Cognitive processing that is unique and distinctive from the remaining emotions.

The development of the basic emotions is linked to the maturation of the mechanisms and neural structures that support the emotional process, they correspond to a certain adaptive function and also have 
specific triggering conditions for each one, their cognitive process, a characteristic subjective experience, a distinctive pattern of nonverbal communication and a different coping style.

Based on the theory of the universality of emotions (Ekman, 1994) and the existence of a prototypical pattern of facial expression for each of them, this standardized model will be used for comparison with the subject of analysis.

b) Differentiated pathways

Recent research (Barlett et al. 2014) shows that the pathway in charge of the control of spontaneous emotion facial expressions is a subcortical extrapyramidal motor system, whereas the performance of voluntary facial expressions is controlled by a cortical pyramidal motor system.

The existence of distinct pathways, albeit with cognitive-emotional interconnections, demonstrates that the neural processes underlying spontaneous and intentional facial expressions are distinct, which will lead to observable differences in facial expression that will be analyzed using the FEAP protocol.

c) Core relational themes.

The third pillar underpinning the protocol is the assumption that certain cognitive interpretations will generate certain emotions and that this occurs generically in any human being. This assertion is based on the cognitive-motivational-relational theory of emotion that includes the proposals of Richard Lazarus (Lazarus, 1991). Lazarus proposes the existence of core relational themes associated with each emotion, which have a strong motivational basis, and reveal the prototypical meaning of that emotion, also allowing to explain certain emotional responses that seem instantaneous and occur in complex situations.

The FEAP protocol is, therefore, a tool designed to detect the congruence/incongruence of emotional facial expression based on the three constructs mentioned above. The absence of congruence may in many cases be linked to an attempt at deception but given the lack of scientific evidence that strongly supports this statement as the only causal relationship, it will be interpreted as an alarm signal that will guide the analyst in the search for other evidence about the truth or falsehood underlying the subject's testimony, and not as an unequivocal sign of deception.

The tool is structured in 4 consecutive phases:

\subsection{PHASE 1. EXPECTED EMOTION:}

Based on the theory of the core relational themes previously exposed, it is stated that each situation intrinsically carries with it an emotion congruent with the valuation of the meaning of this situation, being 
this Expected Emotion denominated. In the face of a dramatic event for an individual, the emotion that would be congruent is assumed to have a negative valence, while in the face of a positive event we expect to find underlying emotions with a positive valence.

\subsection{PHASE 2. EMOTION DISPLAYED:}

In this phase, it is determined which is the facial expression that the subject of analysis presents and therefore, which is the underlying emotion, regardless of the congruence or not with the expected emotion. This analysis is performed using the FACS (Emotional Facial Action Coding System) created by Friesen and Ekman (1978). It is based on the appearance of muscular movements in the face that are coded using Action Units (AUs) in different prototypical configurations of an emotion.

\subsection{PHASE 3. VISUAL COMPARISON.}

Once the expected emotion has been established according to the situation and compared with the emotion presented by the subject, its congruence/incongruence will be established at a first level. It is a first visual and quick analysis that already awakens alarm signals just by applying a brief reflection from an emotional point of view.

\subsection{PHASE 4. FINE ANALYSIS.}

In case the expected emotion and the presented emotion are congruent, it is necessary to study the latter to determine if it is a real emotion or if it is faked. This analysis is performed using the FACS (Emotional Facial Action Coding System) systematized by the NBAM protocol.

NBAM protocol (Nonverbal Behavior Analysis Matrix).

For the analysis of the emotional and behavioral process exposed, the NBAM protocol is used, a tool created and developed by Psychology PhDs Juan Enrique Soto, Rafael López, and Fernando Gordillo, which standardizes the data collection and the inferential logical process from which the final hypotheses are extracted. The tool takes into account elements of a biological nature, such as the facial expression of basic emotions, as well as individual elements that are isolated from a specific individual based on his or her baseline behavior. Therefore, the analysis will be determined by the search for alterations in the individual's habitual behavior, and is performed for each of the non-verbal expressive channels:

-Facial expression: the analysis of facial expressions is performed on the basis of FACS, which encodes each muscular movement of the face. 
- Gestures

- Postures

- Physiological responses

- Proxemics

- Haptic

- Emotional prosody.

- Appearance

For all this, the tool is structured in 4 levels of analysis:

-Level 0. Basal behavior matrix, where a line of the individual's own behavior in neutral situations is established and then compared.

-Level 1. Data matrix: The data is presented objectively on the basis of the extracted frames.

-Level 2. Matrix of inferences: From all these data, logical inferences are made that function as provisional hypotheses of the observed behavior. Each inference is coded and the data from which it is derived is indicated.

-Level 3.Hypothesis matrix: Finally, from the inferences indicated, the definitive hypotheses are elaborated. In the same way, they are ordered and codified, and the inferences from which they come are also marked for a follow-up of all of them.

The process of analysis of the statement culminates with the elaboration of a final hypothesis or result on its compatibility or not with an honest discourse and the congruence of the emotional processes experienced during the narration of the event.

\section{CONCLUSIONS}

The Veracity section (V2) of the SAVE manages to determine, using standardized observation tools and with scientific support, the level of congruence between the verbal message emitted by the subject and the non-verbal communication that accompanies it, where certain emotions underlie.

If discordances appear in the comparison of the expected emotions and the emotions presented, and therefore their message, the analyst will interpret that there are certain alarm signals regarding the honesty of the testimony.

For the verification of the hypothesis of deception, the support of V1 and V3 is essential, which positions SAVE as a tool with a high degree of accuracy due to its multidisciplinary approach in which the conclusions are supported by the analysis of various fields.

Keywords: basic emotions, expected emotion, displayed emotion, congruence, deception. 


\section{REFERENCES}

Bartlett, M. S., Littlewort, G. C., Frank, M. G., Lee, K. (2014). Automatic decoding of facial movements reveals deceptive pain expressions. Curr Biol. 24(7):738-743.

Friesen, E., \& Ekman, P. (1978). Facial action coding system: a technique for the measurement of facial movement. Palo Alto, 3(2), 5.

Ekman, P. (1972). Universals and Cultural Differences in Facial Expressions of Emotion. In J. Cole (Ed.), Nebraska Symposium on Motivation (Vol. 19, pp. 207-282). Lincoln, NE: University of Nebraska Press.

Ekman, P. (1994). Strong Evidence for Universals in Facial Expression: A reply to Russell's mistaken critique. Psychological Bulletin, 115(2), 268-287.

Izard, C. E. (1991). Emotions, personality, and psychotherapy. The psychology of emotions. Plenum Press. doi.org/10.1007/978-1-4899-0615-1.

Lazarus, R. S. (1991). Progress on a cognitive motivational-relational theory of emotion. American Psychologist, 46(8), 819-834.

López, R. M., Domínguez-Muñoz, A., Grau, M., Juárez, A., Jiménez, J., \& Garrido, M. J. (2018). SAVE metaprotocol for behavior analysis. An integrative proposal. In E. Arias, J. Sanmarco, \& X. Camplá (Eds.), XI International Congress of Legal and Forensic Psychology. (pp. 528-541). Granada: Spanish Society of Legal and Forensic Psychology.

López, R.M., Gordillo, F. and Soto, J.E. (2016). NBAM (Nonverbal Behavior Analysis Matrix) protocol. In López, R.M., Gordillo, F. and Grau, M. (2016), Nonverbal behavior beyond communication and language. (pp. 179- 191). Spain: Pirámide.

López, R.M., Gordillo, F., Soto, J.E., Perez, M.A., Salomoni, C. (2016). FEAP protocol (Facial Expression Analysis Protocol). In López, R.M., Gordillo, F. and Grau, M. (2016), Nonverbal behavior beyond communication and language. (pp. 157- 177). Spain: Pirámide.

Tomkins, S. S. (1962). Affect imagery consciousness: Volume I: The positive affects (Vol. 4). Springer publishing company.

Tomkins, S. (1963). Affect imagery consciousness: Volume II: The negative affects. Springer Publishing Company. 